http://jmscr.igmpublication.org/home/ ISSN (e)-2347-176x ISSN (p) 2455-0450

crossref DOI: https://dx.doi.org/10.18535/jmscr/v7i12.31

Journal Of Medical Science And Clinical Research

\title{
Evaluation of the success rate of medical management of ectopic pregnancy in a tertiary level teaching hospital in Kerala" during a three year period from October 2003 and September 2006
}

\author{
Authors \\ Dr B. Presannakumari ${ }^{1}$, Dr Beena Guhan², Dr Nithya ${ }^{3}$ \\ ${ }^{1}$ Professor Obstetrics and Gynecology, Government Medical College, Calicut, Kerala, India \\ ${ }^{2}$ Assistant Professor, Obstetrics and Gynaecology, Government Medical College, Kerala, India \\ ${ }^{3}$ Postgraduate student, Obstetrics and Gynaecology, Government Medical College Calicut, Kerala, India
}

\begin{abstract}
Background: The incidence of ectopic pregnancy is on the rise owing to artificial reproductive techniques and higher number of patients with tubal pathology. Conservative management of ectopic pregnancy is especially important in couples who wish to preserve fertility and those who have had a previous salpingectomy now presenting with ectopic gestation on the other fallopian tube. Methotrexate an antineoplastic drug has revolutionized the conservative management of ectopic gestation with very few side effects on the pregnant woman. Conservative management of ectopic pregnancy by minimally invasive surgery has also gained popularity in recent times

Objective: The purpose of this study is to report our experience with single and multiple doses of intramuscular methotrexate for the treatment of ectopic pregnancy

Material and Methods: All patients who were diagnosed with an ectopic gestation between October 2003 and September 2006 at IMCH Kozikode, Kerala, India were evaluated .Those cases where the serum BhcG levels were up to $10,000 \mathrm{IU} / \mathrm{mL}$ with no intrauterine pregnancy, stable hemodynamic status, rising $B h c G$ in the setting of a negative endometrial curettage and adenexal mass $<4 \mathrm{~cm}$ were considered for conservative management with methotrexate.

Results: The success rate of non surgical management of ectopic pregnancy as a function of initial beta hcG level was maximum when levels were $<1000 \mathrm{mIU} / \mathrm{ml}$ and least when values were $<10,000$. Beta hcG regression after methotrexate administration was faster with lower initial hormone levels

Conclusion: Methotrexate is a revolutionary drug as far as conservative management of ectopic gestation is concerned. Success of treatment is maximum when the initial serum beta hcG levels are low.

Keywords: Conservative management of ectopic gestation.Serum beta hcG level, Methotrexatem.
\end{abstract}

\section{Introduction}

Ectopic pregnancy is reported in about $1-2 \%$ of pregnant women ${ }^{1}$. It is very important to diagnose this condition sufficiently early so that the maternal morbidity and maternal mortality associated with it can be minimised. Incidence of ectopic pregnancy is on the rise. This can be attributed to ART and higher number of patients with tubal pathology but one cannot shut the eyes to the progress in diagnostic modalities - the highly sensitive human chorionic gonadotropin radio immunoassay and vaginal ultrasonography 
which aids in early diagnosis and picking up cases, which may have been undiagnosed in the past $^{2}$.

Availability of a drug which specifically destroys trophoblast- MTX has revolutionised conservative management. Barnhart et al described a diagnostic algorithm which included clinical examination, quantitative serum beta hcg and transvaginal ultrasound. The diagnosis of ectopic pregnancy using this protocol had a sensitivity of $100 \%$ and specificity of $99 \%^{3}$.

Conventionally, ectopic pregnancies are managed by laparotomy and salpingectomy. The more conservative approaches included surgical and non-surgical management. Conservative surgical method is linear salpingostomy. The most popular amongst medical methods is IM methotrexate injection. Surgically administered medical management includes methotrexate, prostaglandins, hyperosmolar glucose, potassium chloride and RU486.
The result of non surgical treatment with single dose methotrexate has been encouraging with high rates of resolution and almost nil complications. But before being accepted as a standard therapy, it is important that its efficacy be tested in a number of clinical settings. The purpose of this study is to report our experience with single and multiple doses of IM methotrexate for the treatment of ectopic pregnancy.

\section{Materials and Methods}

Between October 2003 and September 2006, all patients evaluated in the Department of Obstetrics and Gynaecology, IMCH Kozhikode, Kerala, India, with the non surgical diagnosis of ectopic pregnancy, were considered for methotrexate therapy. Patients were evaluated according to a diagnostic algorithm (Fig.1) that incorporated serum beta hcg titres, vaginal sonography and endometrial curettage. The sensitivity and specificity of this algorithm has been testified by various authors ${ }^{4,5}$.

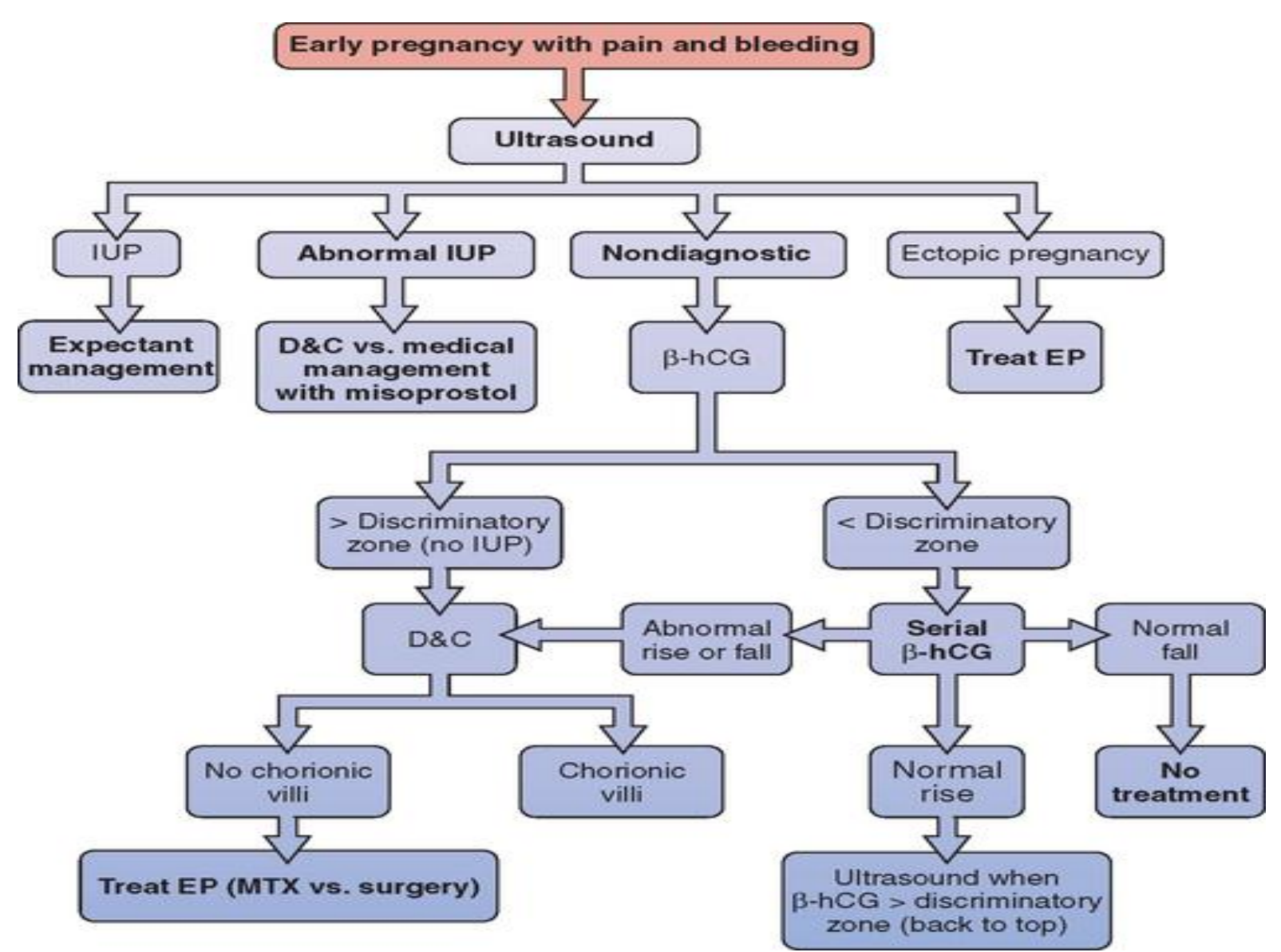

Fig.1 Diagnostic algorithm for ectopic pregnancy 
The inclusion criteria for methotrexate therapy included serum beta hcg levels upto10000mIU/Ml with no intrauterine pregnancy by transvaginal ultrasound, stable hemodynamic status, rising beta hcg levels in the setting of a negative endometrial curettage, adnexal mass with large diameter $<4$ $\mathrm{cm}$. Patients were excluded from medical management and considered as candidates for surgical treatments if:

(1) There was hemodynamic compromise.

(2) Adnexal masses larger than $4 \mathrm{~cm}$ diameter or free fluid in cul-de-sac $>100 \mathrm{ml}$ associated with pelvic pain or cardiac activity in an extrauterine sac.

(3) Serum beta hcg $>10000$.

(4) Biochemical evidence of hepatic dysfunction (AST>50IU/L).

Renal dysfunction (serum creatinine>1.3 $\mathrm{mg} / \mathrm{dl})$.

Hematologic TC $<3000 / \mathrm{mm}^{3}$.

Platelet count $<1$ lakh.

(5) Active pulmonary disease.

(6) A non complaint patient.

(7) Patients who refused medical management.

The protocol for medical management with methotrexate administration included evaluation of serum beta hcg litres, complete blood counts, liver and renal function tests on the day of injection (day0). Serum beta hcg was repeated on days 4 and 7and weekly thereafter until values became $<15 \mathrm{mIU} / \mathrm{ml}$. Blood counts, liver and renalfunction tests were repeated on day7.If the difference between day 4 and 7 beta hcg was $<15 \%$, a repeat dose of MTX was given. AntiD Immunoglobulin was administered for those patients who were $\mathrm{Rh}$ negative. All patients were admitted in the hospital and methotrexate was administered as an intramuscular injection in a dose of $50 \mathrm{mg} / \mathrm{m}^{2}$ in divided doses to each buttock. Patients were counselled regarding the possible side effects of liver function impairment, gastritis, stomatitis and bone marrow depression.

If at any point during the treatment, the patient developed worsening of pelvic pain, with associated peritoneal signs, falling haematocrit and sonological evidence of hemoperitoneum, medical therapy was abandoned and surgical management was proceeded with.

Multidose regimen involved administration of MTX $1 \mathrm{mg} / \mathrm{kg}$ intramuscularly on day1, after baseline beta hcg estimation and alternate day 4 doses with folinic acid $0.1 \mathrm{mg} / \mathrm{kg}$ intramuscularly. Baseline counts, renal and liver function tests are mandatory before methotrexate administration. betahcg is estimated at day 1 ,day3, day 5 and day 7 until levels decrease. Regimen can be repeated for upto 4 doses of each medication. for follow up ,serum beta hcg levels were checked weekly and regimen continued until no longer detected ${ }^{(6,7)}$.

After initiation of a data base, continued prospective monitoring was done for all patients undergoing medical management. The data base included dose of methotrexate administered and the laboratory values at the beginning of treatment. Follow up values and outcomes were obtained from hospital and clinical records and by contacting individual patients if necessary. The operative notes were reviewed of those patients who had to undergone surgery, to have an idea of the nature of surgery and intraoperative findings. The side effects that patients reported during the treatment were also noted from case records.

\section{Statistical Analysis}

The continuous variables were expressed as mean and standard deviation and categorical variables were expressed as frequencies and percentages. Chi square and Mann Whitney tests were done. Data was analysed using SPSS software version 20.0 .

\section{Results}

A total number of 133 ectopic gestations were studied. Amongst these women 67(67\%) were nullipara, 47(35.3\%) were para 1 and 19(14.7\%) multipara. (Fig.2) 


\section{JMSCR Vol||07||Issue||12||Page 171-182||December}

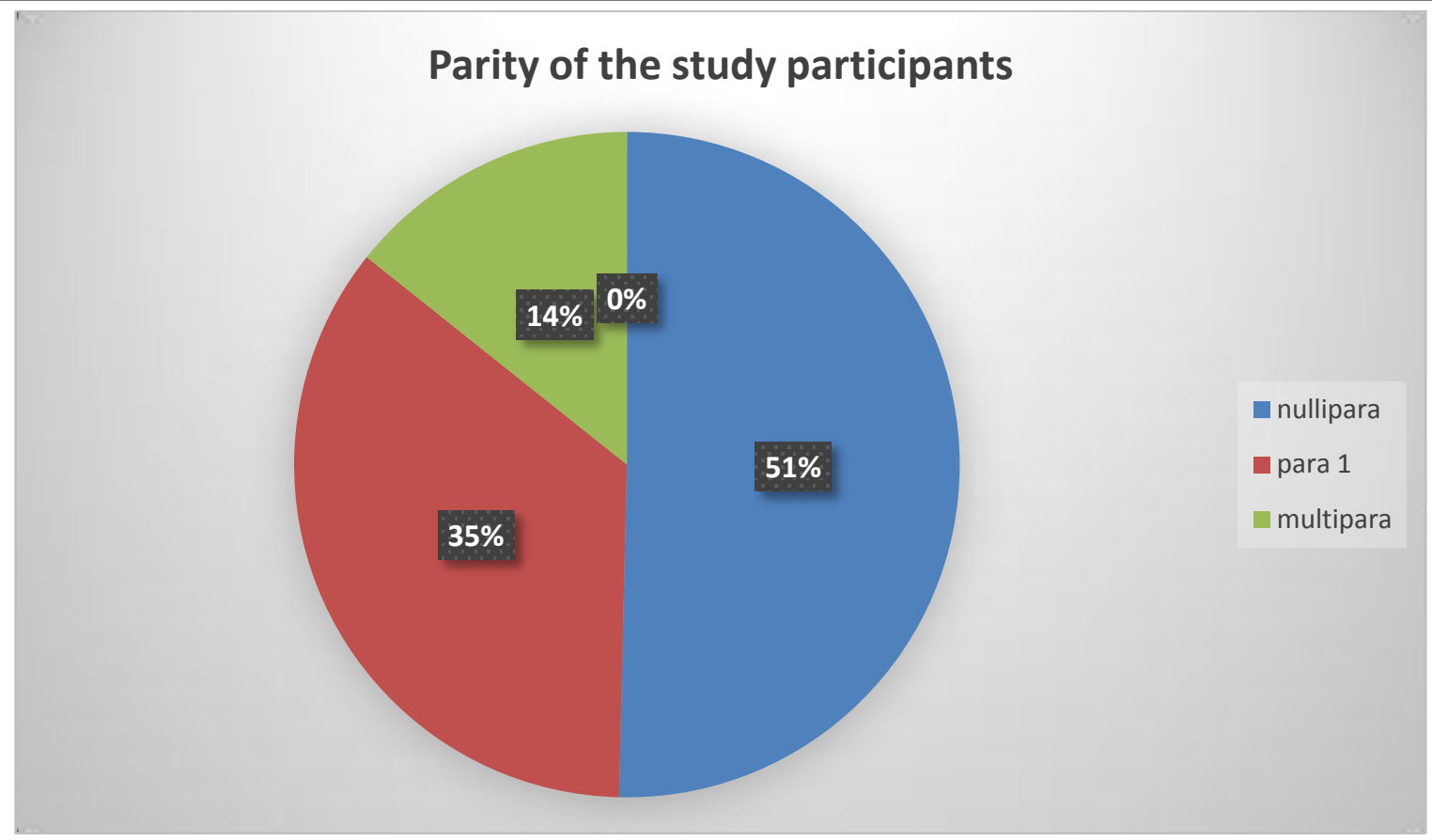

Fig . 2. Parity of study participants.

The risk factors to develop an ectopic gestation identified in the study group were (Fig 3):

a) Previous abortion- 33 (24.8\%)

b) $\mathrm{Cu} \mathrm{T}$ insertion $-7(5.2 \%)$ c) Previous history of ectopic gestation $11(8.3 \%)$

d) Previous sterilization- - 5 (3\%)

e) Previous MTP - 8(6\%)

f) Previous tubal surgery $-3(2.3 \%)$

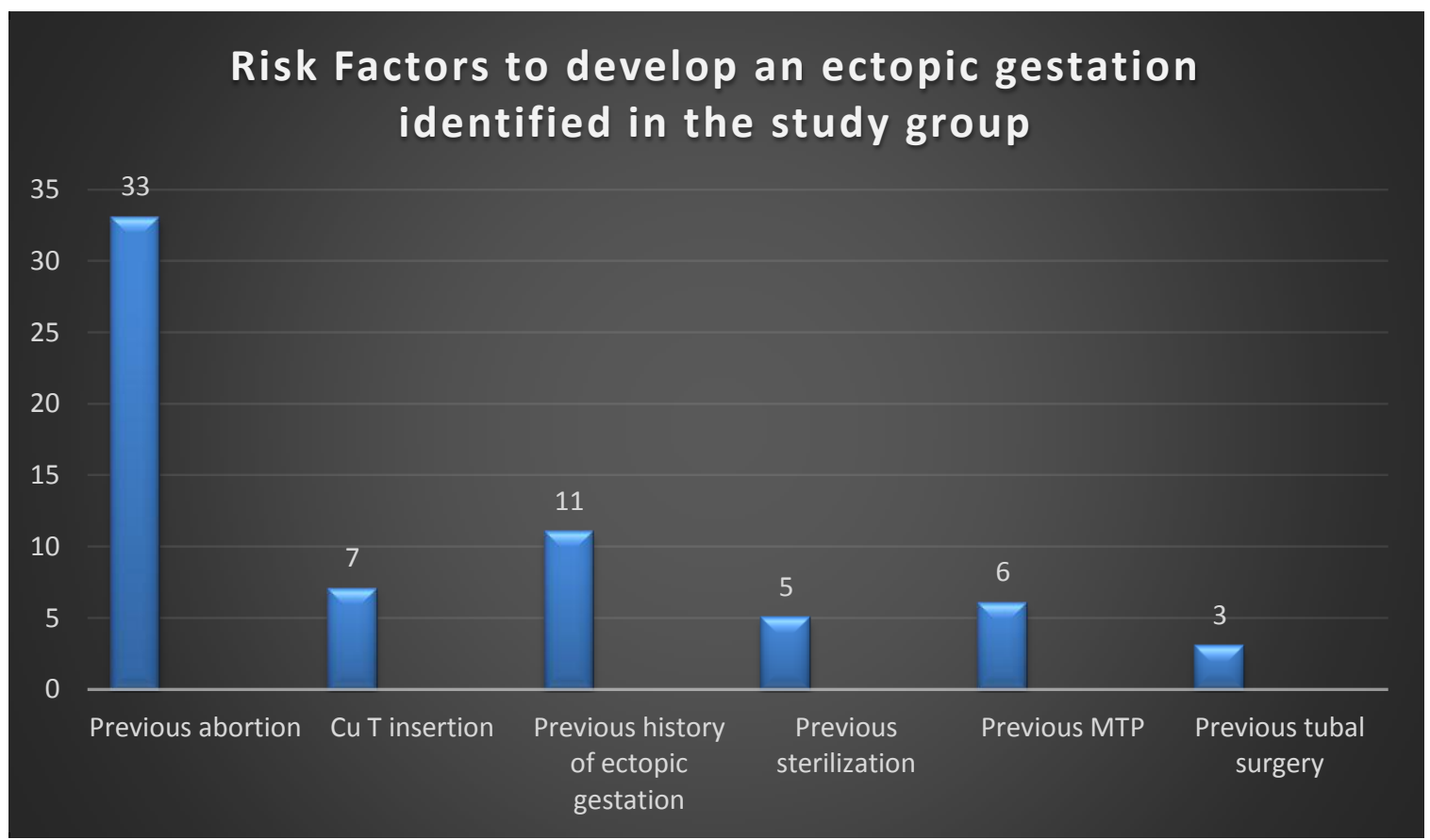

Fig .3.Risk factors for the development of ectopic gestation.

Transvaginal sonography done in these women revealed an ectopic gestational sac in 28(21\%), an adnexal mass in 100(75\%), fluid in POD in
53(39.8\%) .Cardiac activity and fetal pole were demonstrated in the ectopic masses in $2(1.4 \%)$ and $7(5.3 \%)$ cases respectively. 
The success rate of non surgical management of ectopic pregnancy as a function of initial serum Beta HCG levels were also evaluated (Table 1). Out of 77 patients with Beta hcg levels less than 1000 in whom expectant management, single or multi dose of MTX was tried, 72 patients had their Beta hcg returning back to normal (93.5\%).27 patients had their Beta hcg levels between 1001 and 3000, of which treatment was success in 25(92.5\%).11 had levels between 3001 and 5000 of which 10 had successful treatment (90.5\%). Values between 5001 and 10000 were identified in 11 patients of which 8 had serum beta hcg returning to normal (72.5\%). Beta hcg values more than 10000 was observed in 7 cases, among which 5 cases had successful treatment (71.4\%). This was almost similar to the study by Lipscomb etal $^{26}$ where success rates of treatment was maximum (98\%) when beta hcg was less than 1000(Table 2).

Table 1.Success rate of non-surgical management in ectopic pregnancy as a function of initial beta hcg level $(\mathrm{n}=133)$

\begin{tabular}{|c|c|c|c|c|}
\hline Beta hCG & $\begin{array}{c}\text { Expectant } \\
\text { management }\end{array}$ & MTX-1 & $\begin{array}{c}\text { MTX- } \\
\text { multi }\end{array}$ & $\begin{array}{c}\text { Success- } \\
\text { No (\%) }\end{array}$ \\
\hline$<1000$ & 31 & 40 & 6 & $72(93.5 \%)$ \\
\hline $1001-3000$ & 1 & 25 & 1 & $25(92.5 \%)$ \\
\hline $3001-5000$ & 0 & 11 & 0 & $10(90.5 \%)$ \\
\hline $5001-10,000$ & 0 & 10 & 1 & $8(72.5 \%)$ \\
\hline$>10,000$ & 0 & 6 & 1 & $5(71.4 \%)$ \\
\hline
\end{tabular}

Table 2.MTX success rate at different baseline beta hcg level -

\begin{tabular}{|l|c|}
\hline \multicolumn{1}{|c|}{ Initial Beta hCG } & Success rate (\%) \\
\hline$<1000$ & $98 \%$ \\
\hline $1000-1999$ & $93 \%$ \\
\hline $2000-4999$ & $92 \%$ \\
\hline $5000-9999$ & $87 \%$ \\
\hline $10,000-14,999$ & $82 \%$ \\
\hline$>15,000$ & $68 \%$ \\
\hline
\end{tabular}

Lipscomb GH, McComb MC, Stovall TG, N Engl J Med 1999 ;941:1976 
The Beta hcg regression in weeks as a function of initial Beta hcg levels were plotted for single dose MTX (Table 3). Patients in whom the Beta hcg levels were less than 1000 , the mean number of weeks for beta hcg regression was 2.65 +/1.311. When beta hcg levels were in the range of 10000 , the mean number of weeks for beta hcg regression was found to be 4 .
When multidose regimen was administered, a mean of $3.33+/-1.9664$ weeks were required for beta hcg regression when initial values were less than 1000 and over a mean of 4 weeks when initial values were in the order of 16000 (Table 4).

Table 3.betahcg regression in weeks as a function of initial beta hcg level $(n=133)$

Repor

WEEKS
\begin{tabular}{|l|c|r|r|}
\hline BHCG & Mean & N & Std. Deviation \\
\hline 1.00 & 2.6500 & 40 & 1.3311 \\
2.00 & 2.5000 & 14 & 1.4544 \\
3.00 & 2.2727 & 11 & 1.1037 \\
4.00 & 2.1429 & 7 & 1.0690 \\
5.00 & 4.0000 & 4 & 1.4142 \\
6.00 & 4.0000 & 2 & .0000 \\
7.00 & 3.3333 & 3 & 2.5166 \\
8.00 & 4.0000 & 3 & 1.0000 \\
9.00 & 1.0000 & 1 & - \\
10.00 & 4.0000 & 1 & -0000 \\
12.00 & 2.0000 & 2 & - \\
14.00 & 1.0000 & 1 & 2.8284 \\
18.00 & 4.0000 & 1 & 1.3901 \\
25.00 & 3.0000 & 2 & \\
Total & 2.6848 & 92 & \\
\hline
\end{tabular}

a. METHTEX $=1.00$

Table 4.betahcg regression in weeks as a function of initialbetahcg level $(n=133)$

Repor $\mathbf{t}$

WEEKS

\begin{tabular}{|l|c|r|r|}
\hline BHCG & Mean & N & Std. Deviation \\
\hline 1.00 & 3.3333 & 6 & 1.9664 \\
2.00 & 5.0000 & 1 &. \\
10.00 & 2.0000 & &. \\
16.00 & 4.0000 & 1 &. \\
Total & 3.4444 & 1 & .7401 \\
\hline
\end{tabular}

a. METHTEX $=2.00$

Repor

WEEKS

\begin{tabular}{|l|l|r|r|}
\hline BHCG & Mean & N & Std. Deviation \\
\hline 1.00 & 3.3333 & 6 & 1.9664 \\
2.00 & 5.0000 & 1 & - \\
10.00 & 2.0000 & 1 & - \\
16.00 & 4.0000 & 1 & - \\
Total & 3.4444 & 9 & 1.7401 \\
\hline
\end{tabular}

a. METHTEX $=2.00$ 
Expectant management was observed in 32 patients where there was an ectopic gestation, but with no definite fetal pole. Beta hcg regression was satisfactory in 31 cases (96.9\%).Single dose MTX was administered to 86 patients in the same category and treatment was successful in 77(89.5\%). Multidose regimen was administered to only 8 patients out of which 7 had successful outcome $(87.5 \%)$.
Expectant management was not tried when a fetal pole was visualized in the ectopic mass. 6 patients with a fetal pole in the ectopic gestation received single dose and 1 received multi dose MTX regimen out of which $5(83.35 \%)$ and $1(100 \%)$ had favourable outcome respectively. The type of treatment adopted and the outcome obtained did not show any statistically significant association when an ectopic gestation with fetal pole was subjected to therapy. $(\mathrm{P}>0.05)$ (Table 5).

Table 5.Outcome of treatment in the presence and absence of fetal pole

OUTCOME * METHTEX * FET ALPOL Cross tabulation

\begin{tabular}{|c|c|c|c|c|c|c|c|}
\hline \multirow{2}{*}{\multicolumn{4}{|c|}{ FETALPOL }} & \multicolumn{3}{|c|}{ METHTEX } & \multirow[b]{2}{*}{ Total } \\
\hline & & & & .00 & 1.00 & 2.00 & \\
\hline \multirow[t]{9}{*}{ no } & OUTCOME & no & Count & 1 & 9 & 1 & 11 \\
\hline & & & $\%$ within OUTCOME & $9.1 \%$ & $81.8 \%$ & $9.1 \%$ & $100.0 \%$ \\
\hline & & & $\%$ w ithin METHTEX & $3.1 \%$ & $10.5 \%$ & $12.5 \%$ & $8.7 \%$ \\
\hline & & yes & Count & 31 & 77 & 7 & 115 \\
\hline & & & $\%$ w ith in OUTCOME & $27.0 \%$ & $67.0 \%$ & $6.1 \%$ & $100.0 \%$ \\
\hline & & & $\%$ w ith in METHTEX & $96.9 \%$ & $89.5 \%$ & $87.5 \%$ & $91.3 \%$ \\
\hline & Total & & Count & 32 & 86 & 8 & 126 \\
\hline & & & $\%$ w ithin OUTCOME & $25.4 \%$ & $68.3 \%$ & $6.3 \%$ & $100.0 \%$ \\
\hline & & & $\%$ w ith in METHTEX & $100.0 \%$ & $100.0 \%$ & $100.0 \%$ & $100.0 \%$ \\
\hline \multirow[t]{9}{*}{ yes } & OUTCOME & no & Count & & 1 & & 1 \\
\hline & & & $\%$ w ith in OUTCOME & & $100.0 \%$ & & $100.0 \%$ \\
\hline & & & $\%$ w ith in METHTEX & & $16.7 \%$ & & $14.3 \%$ \\
\hline & & yes & Count & & 5 & 1 & 6 \\
\hline & & & $\%$ w ith in OUTCOME & & $83.3 \%$ & $16.7 \%$ & $100.0 \%$ \\
\hline & & & \% w ithin METHTEX & & $83.3 \%$ & $100.0 \%$ & $85.7 \%$ \\
\hline & Total & & Count & & 6 & 1 & 7 \\
\hline & & & $\%$ w ith in OUTCOME & & $85.7 \%$ & $14.3 \%$ & $100.0 \%$ \\
\hline & & & $\%$ w ith in METHTEX & & $100.0 \%$ & $100.0 \%$ & $100.0 \%$ \\
\hline
\end{tabular}

Chi-Square Tests

\begin{tabular}{|ll|c|c|}
\hline FETALPOL & Value & $\begin{array}{c}\text { Asy mp. Sig. } \\
\text { (2-sided) }\end{array}$ \\
\hline no & Pearson Chi-Square & 1.729 & .421 \\
\hline yes & Pearson Chi-Square & .194 & .659 \\
\hline
\end{tabular}

It was not uncommon to see patients with free fluid in pelvis along with ectopic mass. The outcome of conservative management in such patients was also assessed and compared to those without free fluid in pelvis. 21 cases without free fluid in pelvis were subjected to expectant management. 20 achieved treatment success (95.2\%). 53 cases were administered single dose MTX and 6 were given multiodse regimen in which $49(92.5 \%)$ and $5(83.3 \%)$ had successful outcomes respectively.
The remaining 53 cases had presence of free fluid in cul-de sac. Out of which all the 11 cases in which expectant management was observed achieved treatment success (100\%), 39 were given single dose MTX and 3 were given multidose regimen of which $33(84.6 \%)$ and $3(100 \%)$ achieved satisfactory regression in Beta hcg levels respectively.

Once again the mode of treatment and the result obtained did not show a statistically significant association when there was presence of free fluid in the pelvis along with an ectopic mass (Table 6). 
Table 6.Outcome of treatment in the presence and absence of free fluid in cul de sac

Crosstab

\begin{tabular}{|c|c|c|c|c|c|c|c|}
\hline \multirow{2}{*}{ FREFLU } & & & & \multicolumn{3}{|c|}{ METHTEX } & \multirow[b]{2}{*}{ Total } \\
\hline & & & & .00 & 1.00 & 2.00 & \\
\hline \multirow[t]{9}{*}{ no } & OUTCOME & no & Count & 1 & 4 & 1 & 6 \\
\hline & & & $\%$ w ithin OUTCOME & $16.7 \%$ & $66.7 \%$ & $16.7 \%$ & $100.0 \%$ \\
\hline & & & $\%$ w ithin METHTEX & $4.8 \%$ & $7.5 \%$ & $16.7 \%$ & $7.5 \%$ \\
\hline & & yes & Count & 20 & 49 & 5 & 74 \\
\hline & & & $\%$ w ith in OUTCOME & $27.0 \%$ & $66.2 \%$ & $6.8 \%$ & $100.0 \%$ \\
\hline & & & $\%$ w ith in METHTEX & $95.2 \%$ & $92.5 \%$ & $83.3 \%$ & $92.5 \%$ \\
\hline & Total & & Count & 21 & 53 & 6 & 80 \\
\hline & & & $\%$ w ith in OUTCOME & $26.3 \%$ & $66.3 \%$ & $7.5 \%$ & $100.0 \%$ \\
\hline & & & $\%$ w ith in METHTEX & $100.0 \%$ & $100.0 \%$ & $100.0 \%$ & $100.0 \%$ \\
\hline \multirow[t]{9}{*}{ yes } & OUTCOME & no & Count & & 6 & & 6 \\
\hline & & & $\%$ w ithin OUTCOME & & $100.0 \%$ & & $100.0 \%$ \\
\hline & & & $\%$ w ith in METHTEX & & $15.4 \%$ & & $11.3 \%$ \\
\hline & & yes & Count & 11 & 33 & 3 & 47 \\
\hline & & & $\%$ w ith in OUTCOME & $23.4 \%$ & $70.2 \%$ & $6.4 \%$ & $100.0 \%$ \\
\hline & & & $\%$ w ith in METHTEX & $100.0 \%$ & $84.6 \%$ & $100.0 \%$ & $88.7 \%$ \\
\hline & Total & & Count & 11 & 39 & 3 & 53 \\
\hline & & & $\%$ w ith in OUTCOME & $20.8 \%$ & $73.6 \%$ & $5.7 \%$ & $100.0 \%$ \\
\hline & & & $\%$ w ithin METHTEX & $100.0 \%$ & $100.0 \%$ & $100.0 \%$ & $100.0 \%$ \\
\hline
\end{tabular}

Chi-Square Tests

\begin{tabular}{|ll|r|r|}
\hline FREFLUID & Value & $\begin{array}{c}\text { Asymp. Sig. } \\
(2 \text {-sided })\end{array}$ \\
\hline no & Pearson Chi-Square & .954 & .621 \\
\hline yes & Pearson Chi-Square & 2.429 & .297 \\
\hline
\end{tabular}

In the study group of 133,33 cases were identified with no definite adnexal mass on transvaginal sonography. From these 33, 11 cases were subjected to expectant management in which all $11(100 \%)$ had satisfactory decline in serum beta hcg levels.18 cases received single dose MTX of which 16 had favourable outcome $(88.9 \%)$ multidose regimen was followed in the remaining 4 of which all the 4 had successful beta hcg regression(100\%).

A definite adnexal mass was visualized on TVS in 100 cases. 21 such patients underwent expectant management out of which 20 had treatment success (95.2\%).74 had single dose MTX, 5 had multidose MTX. The number of patients who had satisfactory decline in beta hcg levels were $66(89.2 \%)$ and $4(80 \%)$ respectively. Here again the type of treatment and the outcome obtained did not show any statistically significant association when an ectopic gestation with an identifiable adnexal mass was subjected to therapy ( $>0.05$ ). (Table 7) 
Table 7 Outcome of treatment in the presence and absence of adnexal mass on transvaginal sonogram

Crosstab

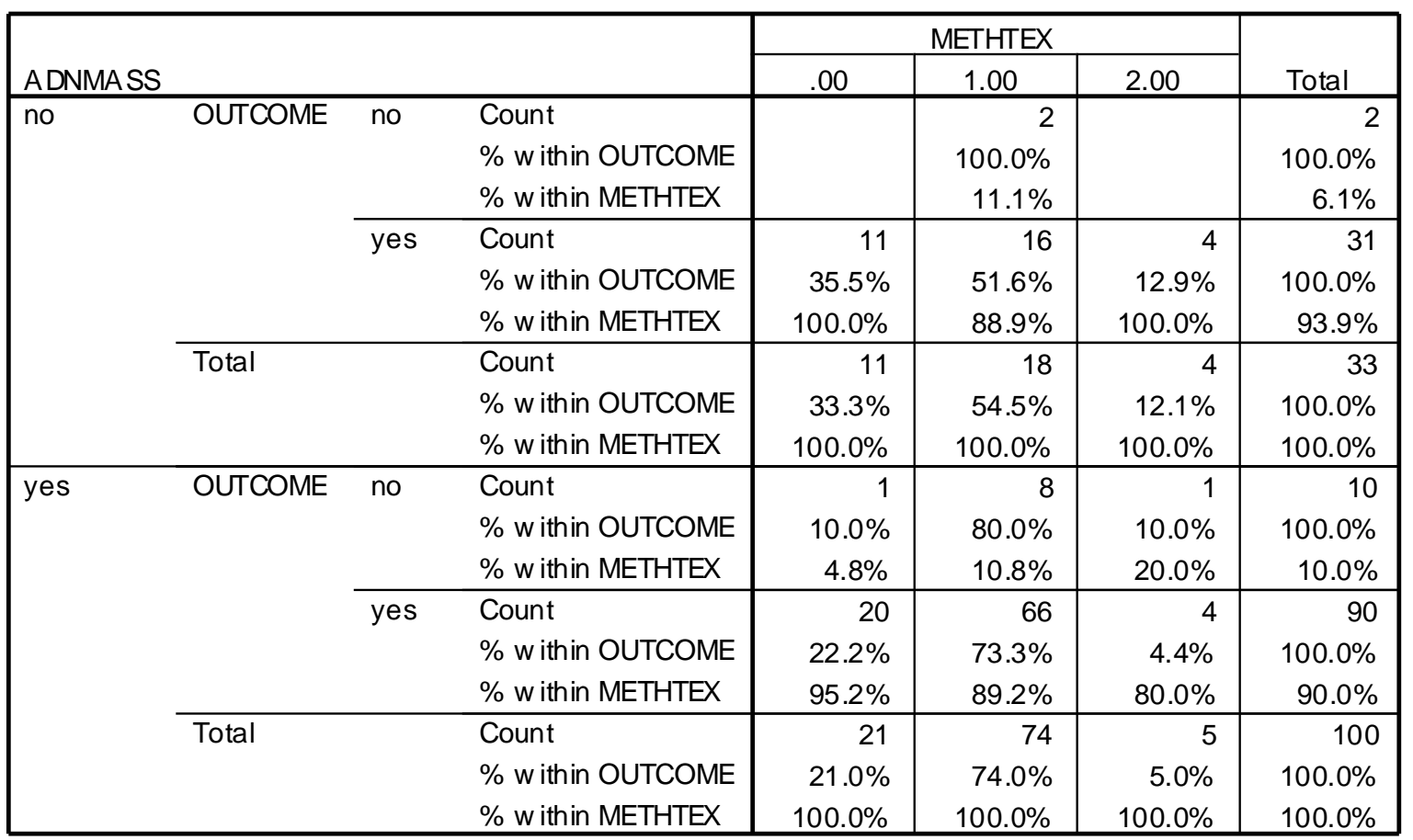

Chi-Square Tests

\begin{tabular}{|ll|c|r|}
\hline ADNMASS & Value & $\begin{array}{c}\text { Asy mp. Sig. } \\
\text { (2-sided) }\end{array}$ \\
\hline no & Pearson Chi-Square & 1.774 & .412 \\
\hline yes & Pearson Chi-Square & 1.250 & .535 \\
\hline
\end{tabular}

\section{Discussion}

The 1980s witnessed the introduction of Methotrexate in the management of ectopic pregnancy. It is a cytotoxic drug which binds to the enzyme dihydrofolate reductase. This enzyme plays a key role in purine synthesis. As a result it interferes with DNA synthesis and disrupts cell multiplication. It can be used both locally and systemically in the management of tubal and non tubal ectopic pregnancies.

\section{Single Dose Methotrexate}

In this regimen, $50 \mathrm{mg} / \mathrm{m}^{2}$ of a single doseof methotrexate is given on the day of diagnosis of ectopic pregnancy (Day 1).Serum beta hcg levels are checked on Day 4, Day 7 and weekly thereafter. The reported success rates of single dose methotrexate in published data ranges from $65-95 \%{ }^{(8,9)}$. The largest reported study on single dose methotrexate has been on 495 women which had a success rate of $90.5 \%{ }^{10}$.

The success rate vary according to inclusion criteria. Some of the studies included women with pregnancy of unknown location or failing gestation where serum beta hcg levels were already on the decline. This may lead to an over estimation of the impact of methotrexate as it is possible that these ectopic pregnancies might have resolved without any treatment.

Success of treatment is lesser when there is presence of fetal cardiac activity in the ectopic mass ${ }^{11}$. This is due to the very high levels of serum beta hcg and a more active trophoblast in these cases.

\section{Predictors of Success}

The single most important predictor of the success of methotrexate in treatment of ectopic pregnancy 
is the initial serumbeta $\mathrm{hcg}^{12,13}$. Failure of medical management was especially high when initial serum beta hcg was more than 10000 $\mathrm{mIU} / \mathrm{ml}^{14}$.The trend of serum beta hcg levels before and after methotrexate administration is also an indicator of treatment success and a predictor of possible tubal rupture ${ }^{14}$.A previous history of ectopic pregnancy appeared to be an independent risk factor for failure of treatment ${ }^{15}$.

The addition of mifepristone to increase the efficacy of MTX failed to demonstrate any benefit except when serum progesterone was greater than $10 \mathrm{ng} / \mathrm{ml}^{16}$.

\section{Multi Dose Regimen}

Multi dose regimen is the alternative to single dose MTX.Here MTX/mg/kg is given on days 1,3 and 5 with folinic acid rescue on day 2,4 and 6 .

A systematic review of over 1300 cases treated either with single dose or multi dose regimen found out the latter was more successful, but associated with significantly more adverse effects $^{17}$. MTX can be administered orally and intravenously with reported success rate of $86 \%$ and $71 \%$ respectively, however there are no obvious advantages over intramuscular administration $^{18,19}$.

\section{Reproductive Outcome}

Thepregnancy rates and tubal patency post MTX treatment have been exclusively studied. Post treatment hysterosalpingogram have demonstrated ipsilateral tubal patency in $77.8 \%$ cases treated with single dose methotrexate ${ }^{20,21}$. These figures are comparable to tubal patency rates after linear salpingostomy ${ }^{22}$. Subsequent pregnancy rates of over $80 \%$ has been demonstrated. The mean time to achieve a pregnancy was $3.2+/-1.1$ months from the time of treatment. More than half of the women who underwent medical management with Methotrexate managed to conceive with intrauterine pregnancies within 1 year of seeking to become pregnant. A previous history of infertility, however was associated with poor reproductive outcome in such patients

\section{Comparison with Surgery}

In a randomised controlled trial where 100 hemodynamically stable women with a tubal ectopic gestation confirmed by laparoscopy, no significant differences were found in primary treatment success or tubal preservation following either multi dose systemic MTX or laparoscopic salpingostomy ${ }^{23}$.Two randomised controlled trials have shown that single dose MTX is as successful as linear salpingostomy in treating selected cases of Ectopic pregnancy ${ }^{24,25}$.

Medical management has an upper hand when economic factors are considered as well.In a study conducted in Netherlands it was demonstrated that MTX therapy could reduce costs if administered to patients with low initial serum beta hcg levels without confirmatory laparoscopy ${ }^{25}$.

The success rates of non surgical management of ectopic pregnancy as evidenced by the regression in serum beta hcg levels in our study was comparable to the study by lipcombs et al where the success rates of conservative management was 98\% when beta hcg levels were below $1000 \mathrm{IU} / \mathrm{L}$. In the same study there were 30 women in whom treatment was unsuccessful whose mean beta hcg values were $13420+/-16590$ and cardiac activity was present in $30 \%$ of these ectopics. Serum betahcg values $>5000$, on ultrasound, moderate to large free fluid, presence of fetal cardiac activity, increase in serum beta hcg levels over a period of 48 hours have all been associated with a failure of medical management ${ }^{27}$.However in our present study we could not obtain a statistically significant association between the mode of treatment adopted and the presence or absence of cardiac activity or free fluid in cul-de sac. This might probably due to the fact that ours was a single institution study, and the sample size was small.

\section{Conclusion}

Ectopic pregnancy is a great masqueraeder. A confident early diagnosis of unruptured ectopic pregnancy increases the chance of managing these cases medically and decreases the incidence of ruptured ectopic gestation. 
Almost all cases of ectopic gestation will have pain abdomen. Single dose intra muscular methotrexate injection can be given to women who are hemodynamically stable and has an initial beta hcg less than $10000 \mathrm{IU} / \mathrm{L}$ and no ultrasonographic evidence of cardiac activity.

For those ectopic pregnancies with cardiac activity, multiple dose regimen may be preferred. The choice of treatment should be guided by patients preference after a detailed discussion about monitoring, outcome, risks and benefits of the approached.

When the serum beta hcg levels are less than 1000 IU/L and patient is stable, expectant management can be adopted. But even when hcg levels are lower than 1000 a risk of tubal rupture exists.

\section{References}

1. Lehner R, Kucera E, Jirecek S, Egarter C,Husslein P. Ectopic pregnancy. Arch Gynecol Obstet 2000 Feb;263(3):87-92.

2. Ankum WM, Van der Veen F, Hamerlynck HV, Lammes FB. Suspected ectopic pregnancy. What to do when human chorionic gonadotropin levels are below the discriminatory zone. Suspected ectopic pregnancy. J Reprod Med 1995;40:525-528

3. Barnhart K, Mennuti MT, Benjamin I, Jacobson S, Goodman D, Coutifaris C. Prompt diagnosis of ectopic pregnancy in an emergency department setting. Obstet Gynecol 1994;84: 1010-5.

4. Chambers SE, Muir BB, Haddad NG. Ultrasound evaluation of ectopic pregnancy including correlation with human chorionic gonadotropin levels. $\mathrm{Br} \quad \mathrm{J}$ Radiol1990; 63:246-50.

5. Stovall TG, Ling DW, Carson SA, Buster JE. Nonsurgical diagnosis and treatment of tubal pregnancy. Fertil Steril 1990;54:537-8

6. Stovall TG N Engl J Med1999;341:1976

7. Barnhart KT, Gosman G, Ashby R, Sammel M.. Obstet Gynecol 2003;101:779.

8. 8.Saraj AJ, Wilcox JG, Najmabadi S, Stein SM, Johnson MB, Paulson RJ. Resolution of hormonal markers of ectopic gestation: a randomized trial comparing single-dose intramuscular methotrexate with salpingostomy. ObstetGynecol 1998; 92: 989-994. 44.

9. Gazvani MR, Baruah DN, Alfirevic Z, Emery SJ. Mifeprostone in combination with methotrexate for the medical treatment of tubal pregnancy: a randomized, controlled trial. Hum Reprod 1998; 13: 1987-1990.

10. Lipscomb GH, Givens VA, Meyer NL, Bran D. Previousectopic pregnancy as a predictor of failure of systemic methotrexate therapy. Fertil Steril 2004; 81: 1221-1224.

11. Pouly JL, Chapron C, Manhes H, Canis M, Wattiez A, Bruhat M-A. Multifactorial analysis of fertility after conservative laparoscopic treatment of ectopic pregnancy in a series of 223 patients. Fertil Steril 1991;56:453-60.

12. 12.Langer R, Bukovsky I, Herman A, Sherman D, Sadovsky G, Caspi E Conservative surgery, for tubal preglmncy. Fertil Steril 1982;38:427-30.

13. Henri-Suchet J, Tesquier L, Loffredo V, Loron Y, De Brux J. Chirurgieconservatrice de la ossesse extra-uterine. In: Brosens JA, editor. Oviducteetsterilite. Paris: Masson, 1979:393-7.

14. Wilson PC. Successful birth after previous tubal ectopic preg- nancies. Med J Aust 1979;2:660-5.

15. Valle JA, Lifchez AS. Reproductive outcome following conser- vative surgery for tubal pregnancy in women with a single fallopian tube. Fertil Steril 1983;39:316-20.

16. Giana M, Dolfin GC, Siliquini PN. Trahemento chirurgico conservativo in 51 caza di gravidenzatubarica. Minerva Ginecol 1978;30:99-102.

17. Stangel JJ, Reyniak JV, Stone ML. Conservative surgical management of tubal pregnancy. ObstetGynecol 1976;48: 241-5. 
18. Mintz L. Conservative treatment in tubal pregnancy. South Med J 1962;56:564-6.

19. Barclay $S$ deC. Conservative surgery in tubal ectopic gesta- tion.Aust NZ J Surg 1961;31:51-63.

20. Paulson JD. The use of carbon dioxide laser laparoscopy in the treatment of tubal ectopic pregnancies. Am J Obstet Gyn- ecol 1992; 167:382-6.

21. Keckstein J, Hepp S, Schneider- V, Sasse V, Steiner R. The contact Nd:YAG laser: a new technique for" conservation of the fallopian tube in unruptured ectopic pregnancy. $\mathrm{Br} \mathrm{J}$ ObstetGynaecol 1990;97:353-6.

22. Thorburn J, Philipson M, Lindblom B. Fertility after ectopic pregnancy) in relation to background factors and surgical treatment. FertilSteril 1988;49:595-601.

23. Slaughter JL, Grimes DA. Methotrexate therapy: nonsurgical management of ectopic pregnancy. West J Med 1995; 162:225-8.

24. Jarvinen PA, Kinnunen O. The treatment of extrauterine pregnancy and subsequent fertility.Int J Fertil 1957;2: 131-5.

25. Jarvinen PA, Kinnunen O. The treatment of extrauterine pregnancy and subsequent fertility.Int J Fertil 1957;2: 131-5.

26. Lipscomb GH, McComb MC, Stovall TG, N Engl J Med1999;941:1976

27. Corsan GH, Karacan M, Qasim S, Bohrer MK, Ransom MX, Kemmann E. Identification of hormonal parameters for successful systemic single-dose methotrexate therapy in ectopic pregnancy. Hum Reprod 1995; 10: 2719-2722.

\section{Abbreviations}

IMCH: Institute of maternal and child health mIU: mili international unit

hcG: Human chorionic gonadotrophins 